\title{
Message from the President of the Oceanographic Society of Japan
}

\author{
Kimio Hanawa
}

(C) The Oceanographic Society of Japan and Springer 2011

The year 2011 is a special year for the Oceanographic Society of Japan (JOS). First, because the JOS was established in 1941, this year is its 70th anniversary. In the 2011 meeting to be held at Kyushu University, Fukuoka, in September, we will conduct a commemorative symposium for the 70th anniversary entitled "Progress in oceanography in Japan and the Oceanographic Society of Japan." In the symposium, we would like to review the progress and future of oceanography in Japan and discuss the role to be carried out by the JOS.

Second, the society's English journal, the Journal of Oceanography (JO), has undergone an important change and become an entirely electronic journal beginning this year with volume 67 . With that change, Springer Japan has become our publisher. Correspondingly, a new editorial board has been established and Dr. Toshiyuki Hibiya, of The University of Tokyo, was invited to become the Editor-in-Chief. A new online manuscript submission and peer-review system, Editorial Manager, also has been introduced and is expected to make the editorial process much faster than it was previously. No publication costs are charged to authors except for reprints. With the society's Japanese journal, Umi-no-Kenkyu (Oceanography in Japan), becoming an electronic journal last year, in 2010 with volume 19, both journals published by the JOS are now in entirely electronic versions. In view of these changes, the JOS decided to publish the JOS Newsletter quarterly beginning this year, to directly and promptly disseminate information concerning the society's activities

\section{K. Hanawa ( $\square)$}

Physical Oceanography Laboratory, Department of Geophysics,

Tohoku University, 6-3 Aramaki-aza-Aoba, Aoba,

Sendai 980-8578, Japan

e-mail: hanawa@pol.gp.tohoku.ac.jp as well as book reviews, meeting reports, and other material.

Third, on March 11, 2011, an extremely powerful earthquake, sometimes referred to as the Great East Japan Earthquake, occurred and the tremendously large tsunami set off by the earthquake struck the east coast of Japan. Tragically, more than 24,000 people were killed or missing as a result of the tsunami. Further, the earthquake and the tsunami damaged the Fukushima-Daiichi Nuclear Power Plant, leaving it in an uncontrollable condition. Subsequently, a huge amount of debris and rubble accumulated in wide coastal areas. It is also known that water polluted by radioactive material was discharged into the ocean from the damaged nuclear power plant, and further pollution of the ocean occurred as radioactive material fell from the atmosphere. There are worries about the destruction of marine ecosystems and the pollution of fish, shellfish, marine plants, and other forms of marine life. The society, a group of ocean scientists, feels a sense of crisis concerning the spread of radioactive materials and resulting destruction of marine ecosystems. The society is committed to doing its best to clarify the degree of pollution and advective-diffusion process of polluted water in the ocean, and will announce the findings on this matter in various ways including publication of papers in JO.

In closing, I would like to declare that the new JO welcomes manuscripts from all researchers of ocean science around the world. Please consider JO as the appropriate journal for publication of your excellent research work.

Kimio Hanawa

President, Oceanographic Society of Japan

Professor, Tohoku University

July 19, 2011 